\title{
Study of Intrauterine Insemination (IUI) among 52 Cases in a Newly Established Infertility Care Centre of Dhaka Medical College Hospital
}

\author{
Rahman $\mathbf{F}^{1}$, Kutubi $A^{2}$, Jabeen $S^{3}$, Akter $Y^{4}$, Sultana $\mathbf{N}^{5}$
}

Conflict of Interest: None Received: 10 July 2016 Accepted: 01 September 2016 www.banglajol.info/index.php/JSSMC

Key Words:

Intrauterine insemination (IUI), Infertility.

\begin{abstract}
:
Intrauterine insemination (IUI) is the therapeutic process of placing washed spermatozoa transcervically into the uterine cavity for the treatment of infertility. IUI theoretically allows a relatively higher number of motile spermatozoa to reach the oocyte. This study is a cross sectional prospective study done on 52 cases in newly started Dhaka Medical College Hospital Fertility Care Centre from October 2015 to March 2016. Among the 52 cases 4 cases became pregnant by IUI (7.7\%) which is equivalent to the success rate observed in other established centers. The outcome suggests that IUI is possible in a relatively new center with limited technology setting. It may be considered as a good treatment option for couples with unexplained infertility, male factor infertility, and anovulation related infertility. Further improvement of this infertility center can bring better outcome in the treatment of infertility in the public sector.
\end{abstract}

[J Shaheed Suhrawardy Med Coll 2016; 8(2): 49-53] DOI: http://dx.doi.org/10.3329/jssmc.v8i2.37243

\section{Introduction}

Intrauterine insemination (IUI) is the therapeutic process of placing washed spermatozoa transcervically into the uterine cavity for the treatment of infertility. IUI theoretically allows a relatively higher number of motile spermatozoa to reach the oocyte. ${ }^{1}$ At present, $16 \%$ of prospective parents seek medical advice for infertility.

A combination of controlled ovarian hyperstimulation $(\mathrm{COH})$ with intrauterine insemination (IUI) remains an important option available to an infertility specialist and is a widely used treatment modality for a broad range of indications. Common indications include cervical factor, mild endometriosis, mild to moderate male factor, ovulatory dysfunction and unexplained infertility. ${ }^{1}$ The reported pregnancy rates per cycle range from 8 to $22 \% .^{2-4}$ The pregnancy rates per IUI cycle are quite variable in the literature due to differences in cause and duration of infertility, concomitant usage or omission of ovarian stimulation, sperm preparation techniques, treatment

1. Dr. Farzana Rahman, Junior Consultant, Gynae, DMCH

2. Dr. Afroza Kutubi, Associate Prof, Gynae, DMCH

3. Dr. Sabrina Jabeen, Project Research Physician, ICDDR'B.

4. Dr. Yasmin Akter, Embryologist, Medical Officer, Gynae, $\mathrm{DMCH}$

5. Prof. Nilufar Sultana, Head, Department Infertility Sub Unit, $\mathrm{DMCH}$

Correspondence to: Dr. Farzana Rahman, Junior Consultant, Gynae, Dhaka Medical College Hospital, Dhaka cycles and number of times IUI is performed during a cycle (single or double). ${ }^{1-4}$

The cumulative pregnancy rates for $\mathrm{COH}$ with IUI vary according to the indications, and are in the range of 20 $33 \% .^{4,5}$ Generally, four cycles of $\mathrm{COH} / \mathrm{IUI}$ are recommended depending on the age of female prior to moving on to assisted reproductive technology (ART)-in vitro fertilization (IVF). ${ }^{3,6}$

Even though $\mathrm{COH} / \mathrm{IUI}$ is a less expensive and simpler form of treatment compared with ART-IVF, it still requires frequent monitoring and supervision under specialist care.The knowledge that the per-cycle pregnancy rates are not very encouraging combined with the time, effort and financial implications of such treatment, attempting a $\mathrm{COH} / \mathrm{IUI}$ cycle could be a challenging decision for the couple.

\section{Material and Method:}

Study Design: Cross sectional Prospective Study.

Study Place: DMCH fertility Care Centre,

Study Period: 5 months; from October 2015-March2016 based on female and male factor;

Inclusion Criteria: Unexplained cause, PCOS, mild endometriosis, male factor like oligospermia. impotence, husband abroad.

Exclusion Criteria: Severe endometriosis, hypospadias, vaginismus, retrograde ejaculation, bilateral tubal block. 
Method: Before each course of treatment, the following tests were performed,

Serum hormone assays (FSH, LH) on the 2nd day of the menstrual cycle.TSH, USG of lower abdomen, Hysterosalpingography/ laparoscopy, semen analysis of husband.

In this case study 52 patient were treated by clomiphene citrate, /aromatoze inhibitor / clomiphene citrate +HCG, / aromatoze $r$ inhibitor+HCG, / FSH. +HCG

On the day of IUI, the husband was instructed to give a semen that was prepared by swip up or double-density gradient method with Pure sperm, The postwash sample parameters were assessed. Under aseptic precautions, IUI was carried out with a soft IUI catheter, with an insemination volume of $0.5 \mathrm{ml}$. After the procedure, the patient was advised 20 minutes of bed rest. All women were provided luteal phase support with natural micronized progesterone vaginal pessaries for 16 days. If menstrual cycle was delayed, urine pregnancy test was carried out. When positive, a transvaginal ultrasound was performed 2 weeks later to confirm a clinical pregnancy. Clinical pregnancy was defined as the presence of an intrauterine gestational sac, confirmed by ultrasound. Higher-order pregnancies were defined as three or more gestational sacs visualized at ultrasound.

\section{Results}

This observational study was performed on 52 couples attended at $\mathrm{DMCH}$ fertility care centre . Appropriate statistical technique was used for data analysis. Results were presented with tables and graphs where applicable.

\section{Socio demographic characteristics of respondents}

\section{Age}

Here age of the female respondent was taken. Minimum and maximum age of them were 20 and 36 accordingly. Mean age was $28.71 \pm 4.58$ years. Maximum number of respondent (15.4\%) aged 30 years. Age was ranged with proportion of respondents in d" 20 (5.8\%), 21-25 (25\%), 26-30 (36.5\%), 31-35 (26.9\%) and e" 30 (5.8\%) accordingly.

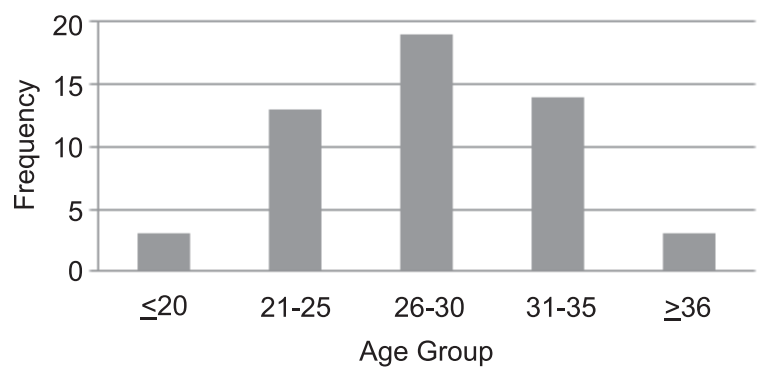

Fig.-1: Age group of the respondent

\section{Education:}

Maximum number of respondent (55.8\%) had education up to HSC or more than this level. Where as the number of illiterate (28.8\%) and up to SSC level (15.4\%) were accordingly.

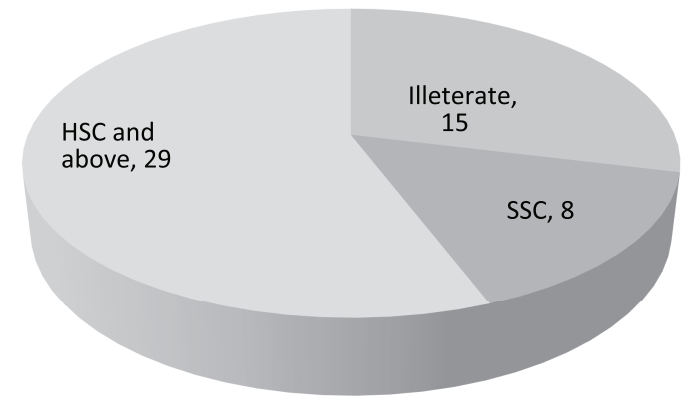

Fig.-2 Education level of the respondent

About $80.0 \%$ respondents had an average financial condition rest lied below average.

Infertility status(Type and cause of infertility)

Proportion of primary subfertility $(67.3 \%)$ with its average duration (6.20 \pm 3.92$)$ was more than secondary subfertility $(32.7 \%)$ and its duration $(5.41 \pm 3.33)$.

Out of 52 cases of infertility, $50 \%$ were due to female cause, $34.6 \%$ due to male cause and rest $15.4 \%$ were due to any unknown cause. Average duration of infertility due to male, female and unknown cause was almost equal $(6.00 \pm 3.76$ years, $6.63 \pm 5.39$ years and $5.69 \pm 3.22$ years).

\begin{tabular}{lcc} 
Types of subfertility & Frequency & Percent (\%) \\
Primary & 35 & 67.3 \\
Secondary & 17 & 32.7 \\
Causes of infertility & & \\
Female cause & 26 & 50.0 \\
Male cause & 18 & 34.6 \\
Unknown cause & 8 & 15.4 \\
\hline
\end{tabular}

It was seen that among the male factor proportion of oligospermia (30.8\%) was higher than other factors (3.8\%).

Female cause was assessed by diagnostic test which included ultrasonography, by TVS, hysterosalpingography and or laparoscopy. In ultrasonography the proportion of poly cystic ovarian syndrome ( $28.8 \%$ ) was more than pelvic inflammatory disease $(11.5 \%)$, fibroid (5.8\%) and endometriosis (3.8\%) accordingly . 


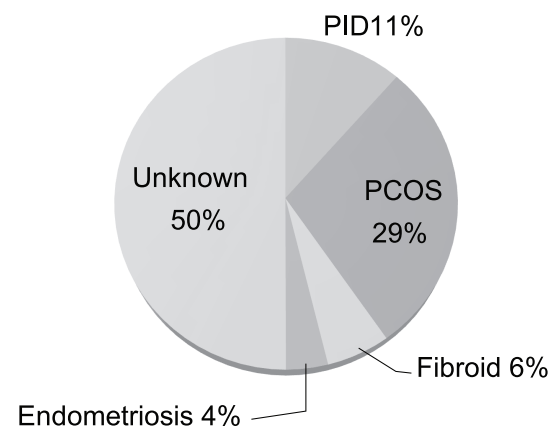

Fig.-3 Ultrasonographic findings of the respondent.

In hysterosalpingography only one patient (1.9\%) was diagnosed with one tubual block. Where as in laparoscopy three patient were diagnosed to have one tubual block $(5.8 \%)$.

Controlled ovarian stimualation was done with aromatase inhibitor (90.4\%), Folicle stimulating hormone (73.1\%), clomifen citrate(13.5\%). These drugs were given in combination. Maximum number of patients who were treated with drugs for infertility, got the combination of two drug $(71.2 \%)$ and rest of them with the combination of three drug (25\%). Inj Human chorionic gonadotrophin was given to all patients on 13th days after doing the TVS.

Folliculometry was done by TVS among 52 female patner dominant follicles were varies from $20 \mathrm{~mm}$ to. $26 \mathrm{~mm}$. Endometrial thickness of the respondents varies from 6to $10 \mathrm{~mm}$. Average thickness of the endometrium was $9.35 \pm 4.004 \mathrm{~mm}$. Of all the 52 respondent only 4 respondent (7.7\%) became pregnant after treatment.

Semen parameter in IUI pre wash showed more oligospermia than post wash $(21.2 \%$ and $19.2 \%)$. Where as proportion of asthenospermia was equal (1.9\%).

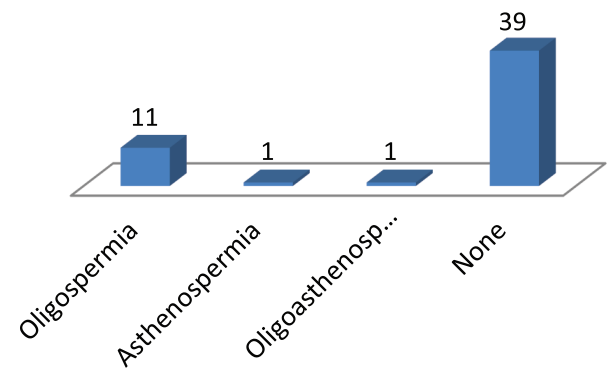

Fig.-4: Serum parameter in IUI pre wash

\section{Discussion:}

A new Infertility Centre has been established at Dhaka Medical College Hospital since 2014. The facilities that available are divided into outdoor service and indoor service. Avaiable outdoor services are : everyday about 20-30 patients get treatment for infertility by doing consultancy USG, TVS, Hysterosalpingography. Indoor services are laparoscopy and hysteroscopy for both diagnostic as well as treatment purpose. In outdoor there is an Andrology Lab and IUI room for IUI. This IUI has started from July 2016, so far 52 cases have undergone IUI.

This study was based upon those 52 cases. Among these 52 cases 23(26.9\%) females have come from 31-35 age group. Majority of the couples 35(67.3\%) had primary subfertility while the rest $17(32.7 \%)$ secondary subfertility. Female factor was predominant $26(50 \%)$ followed by male factor $18(34.6 \%)$. Among the 52 cases $8(15.4 \%)$ couple have been found having both male and female factor. Analysis of female factors revealed that in this study main cause of female factors were anovulation due to PCOS (29\%) followed by PID (11\%) endometriosis (4\%). While male factor analysis had revealed that most of the male suffered from oligospermia (30.8\%) and coital difficulty $(3.8 \%)$.

In this study among 52 cases of IUI 4 cases (7.7\%) became pregnant, The pregnancy rate of IUI is reported to $10-20 \%$ per patient, but the reported rates range from as low as $5 \%$ to as high as $70 \% .{ }^{11}$ Based on the etiology of infertility, the highest rates were reported when IUI was used in patients with anovulation who were undergoing ovulation induction therapy at the time of the IUI treatment, male factor infertility, and unexplained infertility. In patients with endometriosis, the pregnancy rates were the lowest. ${ }^{12}$

Those who became pregnant 2 had oligospermia \& 2 were suffering from unexplained infertility. As part of IUI procedure most of the female patients underwent hysterosalpinography and laparoscopy for evaluation of tubal patency. Among 52 cases 31 females were given ovulation induction by Aromatase inhibitor (L) and human chronic gonadotropin hormone (HCG). 8 cases Clomiphene Citrate and HCG and 13 cases Aromatase inhibitor (L) and Follicular stimulating hormone and human chronoic gonadotropin hormone (HCG) for dominant follicle. Gonadotropins with and without gonadotropin-releasing hormone (GnRH) agonist/antagonist have been studied, along with recombinant human FSH (rFSH). Ragni et al. reported that the daily use of $50 \mathrm{IU}$ of $\mathrm{rFSH}$, combined with a GnRH antagonist, ganirelix, for ovarian stimulation prior to IUI resulted in a live birth rate per couple of $25.7 \% .{ }^{13}$ When the same dose of rFSH was used on alternate days, rFSH produced a live birth rate of $2.9 \% .{ }^{13}$ In another study, $50 \mathrm{IU}$ daily of rFSH was found similar to $75 \mathrm{IU}$ daily of urinary FSH (uFSH) in the outcomes of the number of follicles $>17 \mathrm{~mm}$ and days of stimulation. ${ }^{14}$ The clinical pregnancy rates were $12.7 \%$ for $\mathrm{rFSH}$ and $11.9 \%$ for 
$\mathrm{uFSH} .{ }^{14}$ Thus, the more expensive rFSH was not a costeffective drug for induction of ovulation in IUI cycles. Conversely, Demirol and Gurgan compared rFSH to uFSH and hMG in IUI cycles, and found $\mathrm{rFSH}$ and IUI produced a clinical pregnancy rate of $25.9 \%$ compared to $13.8 \%$ for uFSH and $12.5 \%$ for hMG. ${ }^{15}$ When $\mathrm{rFSH}$ and clomiphene citrate (CC) were compared for ovulation induction with IUI in couples with unexplained and male factor infertility, the cumulative pregnancy rate was $38 \%$ for CC-IUI group versus $34.3 \%$ for the rFSH-IUI group. ${ }^{43}$

The number of mature follicles (17 $\mathrm{mm}$ in diameter or more) is another prognostic factor in IUI success, where the presence of 3-4 mature follicles was associated with higher pregnancy rates and a lower incidence of high-order multiple pregnancies. ${ }^{14}$ Other prognostic factors included female age, duration of infertility and amount of motile sperm. ${ }^{19}$

Cochrane discussed about the effectiveness of IUI in the treatment of unexplained infertility. Verhulst et al. conducted a Cochrane review to assess the effectiveness of IUI in the treatment of unexplained infertility. ${ }^{17}$ Rest of the 2 cases were for Male factor oligospermia. The female partner got concieved in first attempt of IUI. In a Cochrane review it was clearly shown that there is insufficient evidence to conclude whether IUI is effective or not in moderate and mild male infertility. ${ }^{20}$ In the present study pregnancy rate per cycle was $7.7 \%$. Isa et al found pregnancy rate of $8.45 \%$ in cases of unexplained infertility. Ashrafi et al. found pregnancy rate per cycle as $19.9 \%$; best results were found in patients of unexplained, primary infertility, less than 5-year duration, and IMC (inseminated motile sperm count) $>30 \times 10^{6} .{ }^{21}$

\section{Conclusion:}

This study suggests that IUI may be effective in a newly developed medical setting. It may be considered as a good first-line invasive treatment for couples with unexplained infertility, male factor infertility, and patients with anovulation. More study with large number of population is needed to further establish the effectiveness of \& success of IUI.

\section{Recommendation:}

Now a days worldwide infertility problem is increasing day by day. It is also a major problem for our country. However due to high expenses people suffering from infertility are mostly unable to avail this treatment. IUI service in Dhaka medical college offers infertility treatment almost free of cost which is within the reach of poor patients. Infertility centre of Dhaka Medical College has set an example for the other government hospitals and centers which should come forward with such low cost infertility treatment settings and thus provide IUI treatment for the low socio economic people of our country suffering from infertility.

\section{Referrences}

1. Duran HE, Morshedi M, Kruger T, Oehninger S. Intrauterine insemination: A systematic review on determinants of success. Hum Reprod Update. 2002;8:373-84.

2. Bagis T, Haydardedeoglu B, Kilicdag EB, Cok T, Simsek E, Parlakgumus AH. Single versus double intrauterine insemination in multi-follicular ovarian hyperstimulation cycles: A randomized trial. Hum Reprod. 2010;25:1684-90.

3. Nuojua-Huttunen S, Tomas C, Bloigu R, Tuomivaara L, Martikainen $H$. Intrauterine insemination treatment in subfertility: An analysis of factors affecting outcome. Hum Reprod. 1999;14:698-703.

4. Guzick DS, Carson SA, Coutifaris C, Overstreet JW, FactorLitvak P, Steinkampf MP, et al. Efficacy of superovulation and intrauterine insemination in the treatment of infertility. N Engl J Med. 1999;340:177-83

5. C. Keck, C. Gerber-Schafer, C. Wilhelm, D. Vogelgesang, and M. Breckwoldt, "Intrauterine insemination for treatment of male infertility," International Journal of Andrology, vol. 20, pp. 55-64, 1997

6. Dickey RP, Taylor SN, Lu PY, Sartor BM, Rye PH, Pyrzak R. Effect of diagnosis, age, sperm quality, and number of preovulatory follicles on the outcome of multiple cycles of clomiphene citrate-intrauterine insemination. Fertil Steril. 2002;78:1088-95.

7. Hughes EG. Stimulated intra-uterine insemination is not a natural choice for the treatment of unexplained subfertility: 'Effective treatment' or 'not a natural choice'? Hum Reprod. 2003;18:912-4. [PubMed]

8. Van Rumste M, Custers I, van der Veen F, van Wely M, Evers $\mathrm{J}$, Mol B. The influence of the number of follicles on pregnancy rates in intrauterine insemination with ovarian stimulation: A meta-analysis. Hum Reprod Update. 2008;14:563-70.[PubMed]

9. Wainer R, Albert M, Dorion A, Bailly M, Bergere M, Lombroso R, et al. Influence of the number of motile spermatozoa inseminated and of their morphology on the success of intrauterine insemination. Hum Reprod. 2004;19:2060-5. [PubMed]

10. Tomlinson M, Amissah-Arthur J, Thompson K, Kasraie J, Bentick B. Infertility: Prognostic indicators for intrauterine insemination (IUI): Statistical model for IUI success. Hum Reprod. 1996;11:1892-6.

11. N. C. Allen, C. M. Herbert, III, W. S. Maxson, B. J. Rogers, M. P. Diamond, and A. C. Wentz, "Intrauterine insemination: a critical review," Fertility and Sterility, vol. 44, no. 5, pp. 569-580, 1985. View at Google Scholar

12. K. Ahinko-Hakamaa, H. Huhtala, and H. Tinkanen, "Success in intrauterine insemination: the role of etiology," Acta Obstetricia et Gynecologica Scandinavica, vol. 86, no. 7, pp. 855-860, 2007. View at Publisher - View at Google Scholar . View at PubMed.

13. G. Ragni, F. Alagna, C. Brigante et al., "GnRH antagonists and mild ovarian stimulation for intrauterine insemination: a randomized study comparing different gonadotrophin dosages," Human Reproduction, vol. 19, no. 1, pp. 54-58, 2004. View at Publisher · View at Google Scholar 
14. S. Gerli, M. L. Casini, V. Unfer, L. Costabile, V. Bini, and G. C. Di Renzo, "Recombinant versus urinary follicle-stimulating hormone in intrauterine insemination cycles: a prospective, randomized analysis of cost effectiveness," Fertility and Sterility, vol. 82, no. 3, pp. 573-578, 2004. View at Publisher - View at Google Scholar · View at PubMed

15. Demirol and T. Gurgan, "Comparison of different gonadotrophin preparations in intrauterine insemination cycles for the treatment of unexplained infertility: a prospective, randomized study," Human Reproduction, vol. 22, no. 1, pp. 97-100, 2007. View at Publisher · View at Google Scholar · View at PubMed

16. T. Dankert, J. A. Kremer, B. J. Cohlen et al., "A randomized clinical trial of clomiphene citrate versus low dose recombinant $\mathrm{FSH}$ for ovarian hyperstimulation in intrauterine insemination cycles for unexplained and male subfertility," Human Reproduction, vol. 22, no. 3, pp. 792-797, 2007. View at Publisher · View at Google Scholar · View at PubMed

17. S.M. Verhulst, B. J. Cohlen, E. Hughes, M. J. Heineman, and E. te Velde, "Intra-uterine insemination for unexplained subfertility," The Cochrane Database of Systematic Reviews, no. 4, Article ID CD001838, pp. 1-82, 2006. View at Publisher - View at Google Scholar · View at PubMed.

18 M.R. Khalil, P. E. Rasmussen, K. Erb, S. B. Laursen, S. Rex, and L. G. Westergaard, "Homologous intrauterine insemination.
An evaluation of prognostic factors based on a review of 2473 cycles," Acta Obstetricia et Gynecologica Scandinavica, vol. 80, no. 1, pp. 74-81, 2001. View at Publisher · View at Google Scholar

19. M. J. Tomlinson, J. B. Amissah-Arthur, K. A. Thompson, J. L. Kasraie, and B. Bentick, "Prognostic indicators for intrauterine insemination (IUI): statistical model for IUI success," Human Reproduction, vol. 11, no. 9, pp. 18921896, 1996. View at Google Scholar

20. A.J. Bensdorp, B.J. Cohlen, M.J. Heineman, P. Vandekerckhove

- Intra-uterine insemination for male subfertility

- Cochrane Database Syst Rev (4) (2007), p. CD000360

- $\quad$ 17. M.M. Van Rumste, I.M. Custers, F. Van der Veen, M. Van Wely, J.L. Evers, B.W. Mol

- The influence of the number of follicles on pregnancy rates in intrauterine insemination with ovarian stimulation: a meta-analysis

- Hum Reprod Update, 14 (2008), pp. 563-570

21 M. Ashrafi, M. Rashidi, A. Ghasemi et al., "The role of infertility etiology in success rate of intrauterine insemination cycles: an evaluation of predictive factors for pregnancy rate," International Journal of Fertility and Sterility, vol. 7, no. 2, pp. 100-107, 2013. 